\title{
Characterization of Lactobacillus salivarius strains B37 and B60 capable of inhibiting IL-8 production in Helicobacter pylori- stimulated gastric epithelial cells
}

Wimonrat Panpetch ${ }^{1}$, Jennifer K. Spinler ${ }^{2,3}$, James Versalovic ${ }^{2,3}$ and Somying Tumwasorn ${ }^{4 *}$

\begin{abstract}
Background: Interleukin (IL)-8 is the key agent for initiating an inflammatory response to infection with Helicobacter pylori. Some strains of Lactobacillus spp. are known to colonize the stomach and suppress inflammation caused by H. pylori. In this study, we characterized two gastric-derived lactobacilli, Lactobacillus salivarius (LS) strains B37 and B60, capable of inhibiting H. pylori-induced IL-8 production by gastric epithelial cells.

Results: Conditioned media from LS-B37 and LS-B60 suppressed H. pylori-induced IL-8 production and mRNA expression from AGS cells without inhibiting H. pylori growth. These conditioned media suppressed the activation of NF-KB but did not suppress c-Jun activation. IL-8 inhibitory substances in conditioned media of LS-B37 and LSB60 are heat-stable and larger than $100 \mathrm{kDa}$ in size. The inhibitory activity of LS-B37 was abolished when the conditioned medium was treated with a-amylase but still remained when treated with either proteinase K, trypsin, lipase or lysozyme. The activity of LS-B60 was abolished when the conditioned medium was treated with either amylase or proteinase $\mathrm{K}$ but still remained when treated with lysozyme. Treatment with lipase and trypsin also significantly affected the inhibitory activity of LS-B60 although the conditioned medium retained IL-8 suppression statistically different from media control.

Conclusions: These results suggest that L. salivarius strains B37 and B60 produce different immunomodulatory factors capable of suppressing H. pylori-induced IL-8 production from gastric epithelial cells. Our results suggest that the large, heat-stable immunomodulatory substance(s) present in the LCM of LS-B37 is a polysaccharide, while the one(s) of LS-B60 is either complex consisting of components of polysaccharide, lipid and protein or includes multiple components such as glycoprotein and lipoprotein.
\end{abstract}

Keywords: Lactobacillus salivarius, Helicobacter pylori, Interleukin-8, Anti-inflammatory, Probiotic

\section{Background}

Helicobacter pylori is a well-known gastric pathogen which causes gastroduodenal inflammation, peptic ulceration and gastric cancer $[1,2]$. H. pylori infection induces the production of pro-inflammatory cytokines and chemokines such as interleukin (IL)-1 $\beta$, IL-6, IL-8, IL-23 and tumor necrosis factor (TNF)- $\alpha$ [3-5] resulting in gastric inflammation characterized by the infiltration

\footnotetext{
* Correspondence: somying.T@chula.ac.th

${ }^{4}$ Department of Microbiology, Faculty of Medicine, Chulalongkorn University, Bangkok 10330, Thailand

Full list of author information is available at the end of the article
}

of plasma cells, lymphocytes, neutrophils, and monocytes within gastric mucosa $[5,6]$. IL- 8 secreted by gastric epithelial cells is a potent neutrophil-activating and chemotactic agent $[7,8]$ which plays a major role in triggering the mucosal inflammation caused by $H$. pylori [9-13]. Increased levels of IL-8 in gastric juice and biopsy samples have been reported in patients with $H$. pylori infection [10, 11]. In addition, the levels of IL-8 mRNA in the gastric mucosa of $H$. pylori-infected patients correlate significantly with the severity of gastritis $[14,15]$ and the risk of gastric cancer [16]. 
Symptomatic subjects diagnosed with $H$. pylori infection generally receive eradication therapy. However, bacterial resistance to antibiotics and side effects which contribute to poor patient compliance result in suboptimal eradication rates [17, 18]. Probiotics have been shown to confer beneficial effects and are recommended as an adjunct in the treatment of $H$. pylori $[18,19]$. Suppression of pro-inflammatory cytokine secretion by gastric epithelial cells is a mechanism of probiotic action which has been shown by numerous reports $[20,21]$ and considered as an approach to prevent gastric cancer [22]. L. salivarius UCC118 inhibited H. pylori-induced IL-8 production of AGS gastric epithelial cell by decreasing the function of the Cag secretion system [23]. L. acidophilus $\mathrm{LA} 5^{\circ}$ was shown to reduce IL-8 production induced by $H$. pylori in MKN45 gastric epithelial cells by inactivating the Smad7 and nuclear factorkappa B (NF-kB) pathways [24]. Moreover, L. gasseri OLL2716 (LG21) was found to suppress $H$. pylori-induced IL-8 production in MKN45 gastric epithelial cells and decrease the level of IL-8 in the gastric mucosa of H. pylori-infected patients [25]. We previously reported eight isolates of Lactobacillus spp. which inhibited IL-8 secretion from $H$. pylori-infected AGS cells [26]. Among these lactobacilli, L. salivarius B101, L. rhamnosus B103 and L. plantarum XB7 suppressed IL-8 mRNA expression and the activation of NF- $\mathrm{kB}$ whereas $L$. plantarum XB7 also suppressed c-Jun activation. L. salivarius B37, L. salivarius $\mathrm{B} 60$ and the other three strains inhibited the secretion of IL- 8 but did not interfere with IL- 8 gene transcription after co-culture for $4 \mathrm{~h}$ with AGS cells.

In this study, we characterized the mechanism by which the previously identified $L$. salivarius B37 and B60 strains suppress IL-8 production from $H$. pylori-induced gastric epithelial cells. We hypothesized that $L$. salivarius B37 and B60 may suppress IL-8 gene expression at other time points or affect IL-8 production posttranscriptionally or post-translationally. The results of this present study demonstrated that L. salivarius B37 and $L$. salivarius $\mathrm{B} 60$ produce distinct active components that inhibit NF- $\mathrm{kB}$ activation and suppress downstream transcription of $H$. pylori-induced IL-8 mRNA.

\section{Results}

Gastric-derived L. salivarius strains B37 and B60 suppress IL-8 production in $H$. pylori-induced AGS cells

L. salivarius B37 (LS-B37) and L. salivarius B60 (LSB60) are different strains as determined by random amplified polymorphic DNA (RAPD) and repetitivesequence-based PCR (rep-PCR) fingerprinting (data not shown). L. salivarius B78 (LS-B78), which does not suppress IL-8, was included as a negative control. Immunomodulatory activity of substances from Lactobacillus conditioned media (LCM) was investigated by co-incubation with AGS cells either alone or in combination with viable $H$. pylori ATCC 43504. LCM of both LS-B37 and LS-B60 significantly $(p<0.001)$ suppressed IL-8 production in $H$. pylori-stimulated AGS cells, where LCM of LS-B78 did not suppress IL-8 production as expected (Fig. 1, Additional file 1). Trypan blue dye exclusion ( $>90 \%$, data not shown) indicated that IL-8 suppression by LS-B37 and LS-B60 was not due to cytotoxicity on AGS cells. LCM from LS-B37 and LS-B60 did not stimulate IL-8 production when co-incubated with AGS cells in the absence of $H$. pylori (Fig. 1, Additional file 1). In addition, $5 \% \mathrm{v} / \mathrm{v}$ LCM in RPMI medium did not inhibit the growth of $H$. pylori (data not shown).

\section{Secreted factors from $L$. salivarius strains B37 and B60 diminished IL-8 gene expression}

Quantitative reverse transcription polymerase chain reaction (qRT-PCR) was used to determine the effect of LCM on IL- 8 gene transcription. Since it was previously shown that LCM of LS-B37 and LS-B60 did not suppress IL-8 transcription after co-incubation with AGS cells for $4 \mathrm{~h}$ [26], the suppressive effect of these LCM was tested further at various time points. $H$. pylori-stimulated AGS cells were treated with LCM for 2, 4 and $6 \mathrm{~h}$ prior to total RNA isolation. IL-8 gene expression at $2 \mathrm{~h}$, relative to gapdh, was significantly down-regulated approximately 0.4 and 0.3 fold with the treatment of LCM from LS-B37 $(p<0.0001)$ and LS-B60 $(p<0.0001)$, respectively. Unexpectedly, LCM from LS-B37 also down-regulated IL-8 gene expression approximately 0.3

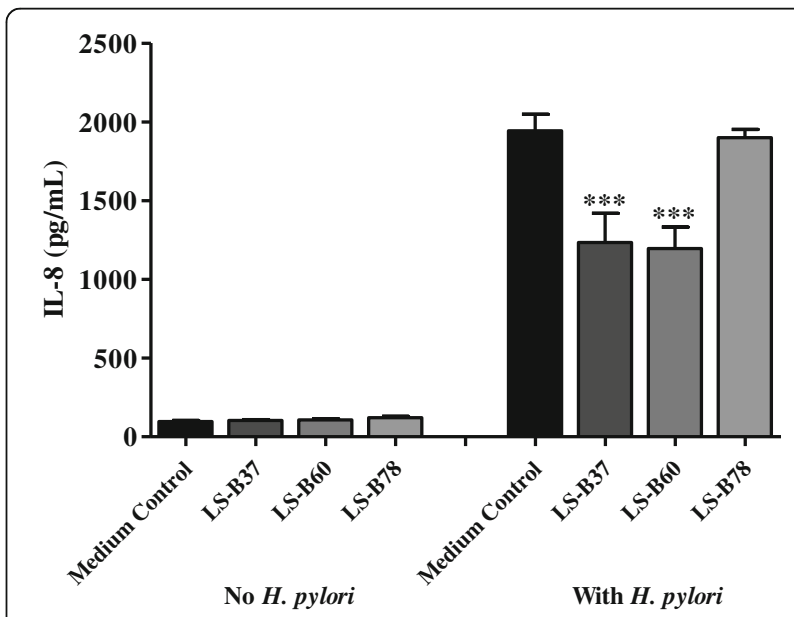

Fig. 1 Specific strains of gastric-derived L. salivarius suppress IL-8 production by $H$. pylori-induced AGS cells. LCM from three strains of L. salivarius were tested for the ability to suppress IL-8 production from AGS cells stimulated by $H$. pylori. AGS cells were incubated with LCM in the presence or absence of H. pylori ATCC43504 for $24 \mathrm{~h}$ and IL-8 secretion was measured by ELISA. The results were from three independent experiments in triplicate and expressed as the mean \pm SEM, ${ }^{* *} p<0.001$ as compared to medium control 
fold $(p<0.0007)$ at $4 \mathrm{~h}$. In addition, LCM from both strains did not affect IL- 8 gene expression at $6 \mathrm{~h}$ (Fig. 2, Additional file 2).

\section{Secreted factors from L. salivarius strains B37 and B60 inhibit NF-KB activation}

$H$. pylori induces various signaling pathways resulting in phosphorylation of transcription factors NF- $\mathrm{kB}$ and activator protein-1 (AP-1) and downstream transcription of IL-8 in gastric epithelial cells [27-29]. To determine the effect of immunomodulatory substances produced by LSB37 and LS-B60 on the activation of NF-kB and AP-1, the concentrations of phosphorylated subunits p65 (p-NF-kB p65) and c-Jun (p-c-Jun) were assayed by Western blot. $H$. pylori-stimulated AGS cells were treated with LCM from either LS-B37 or LS-B60 for 0.25, 0.5, 1, 2 and 3 h. Treatment of LCM from LS-B37 decreased the concentration of p-NF-kB p65 at $15 \mathrm{~min}(28.52 \%, p<0.01$, Fig. 3, Additional file 3) and no significant effects were found at other time points. Treatment with LS-B60 LCM resulted in a significant decrease in $\mathrm{p}-\mathrm{NF}-\mathrm{\kappa} \mathrm{B}$ p65 (38.29\%, $p<0.01$, Fig. 3, Additional file 3) only at $2 \mathrm{~h}$. In contrast, LCM from both strains did not suppress p-c-Jun at any studied time point (data not shown).

The immunomodulatory substances in LCM of $L$. salivarius strains B37 and B60 are heat-stable and larger than $100 \mathrm{kDa}$

Heat treatment and size fractionation of LCM were performed in order to characterize the physical nature of the IL-8 inhibitory substances. LCM from LS-B37 and LS-B60 were heated to $100{ }^{\circ} \mathrm{C}$ for $0.25,0.5,1$ and $2 \mathrm{~h}$ and assayed for IL-8 suppression by an enzyme-linked immunosorbent assay (ELISA). Heat-treated LCM of LS-B37 and LS-B60 at all time retained inhibitory activity of $H$. pylori-induced IL-8 production in AGS cells when compared with MRS control ( $p<0.001$, Fig. 4a, Additional file 4).

Amicon ${ }^{\otimes}$ Centrifugal Filters $(3 \mathrm{kDa}, 50 \mathrm{kDa}$ and $100 \mathrm{kDa}$ ) were used to size fractionate LS-B37 and LSB60 LCM and each fraction was tested for inhibitory activity on $H$. pylori-induced IL- 8 production. Fractions containing substances $>100 \mathrm{kDa}$ significantly suppressed IL-8 production as compared with MRS control $(p<0.001)$, whereas those containing substances $<3 \mathrm{kDa},<50 \mathrm{kDa}$, and $<100 \mathrm{kDa}$ did not suppress $H$. pylori-induced IL-8 production (Fig. 4b, Additional file 5).

Enzyme sensitivity of the immunomodulatory substances in LCM of $L$. salivarius strains B37 and B60 indicates differences in chemical nature

To determine the chemical nature of IL-8 inhibitory substances in LS-B37 and LS-B60 LCM, treatments with $\alpha$-amylase, lipase, proteinase $K$, trypsin, and lysozyme were performed. LCM from LS-B37 and LS-B60 were incubated with each of these enzymes for $6 \mathrm{~h}$ and then tested for $H$. pylori-induced IL-8 production. Treatment of LS-B37 LCM with $\alpha$-amylase abolished IL- 8 suppression as compared to media control $(p>0.066)$ and nontreated LCM ( $>4$ fold change, $p<0.0001$ ), while treatment with lipase, proteinase $K$, trypsin, and lysozyme did not

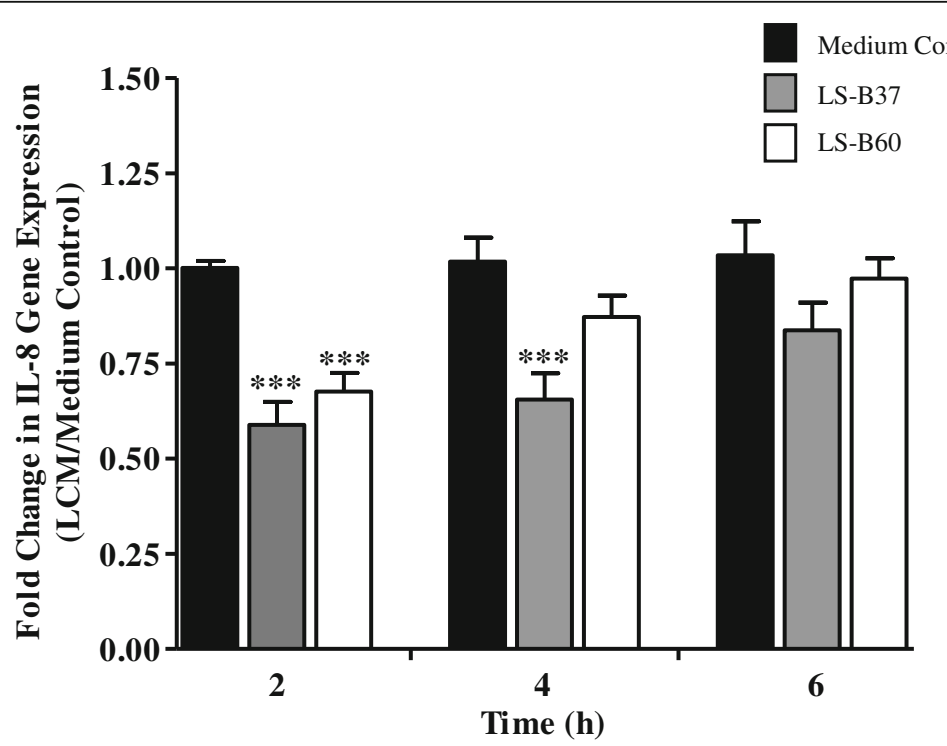

Fig. 2 L. salivarius-produced factors suppress IL-8 transcription in AGS cells. IL-8 gene expression was determined in H. pylori-induced AGS cells after incubation with medium control or LCM from L. salivarius. Gene expression was examined using qRT-PCR with primers specific to IL-8 and GAPDH transcripts. Quantitative gene expression data were normalized to housekeeping gene, GAPDH. The experiments were performed three times independently, each in triplicate. Fold change of IL-8 gene expression was calculated in relative to medium control, and results represent the mean $\pm \mathrm{SEM}^{* * *} p<0.001$ as compared to medium control 


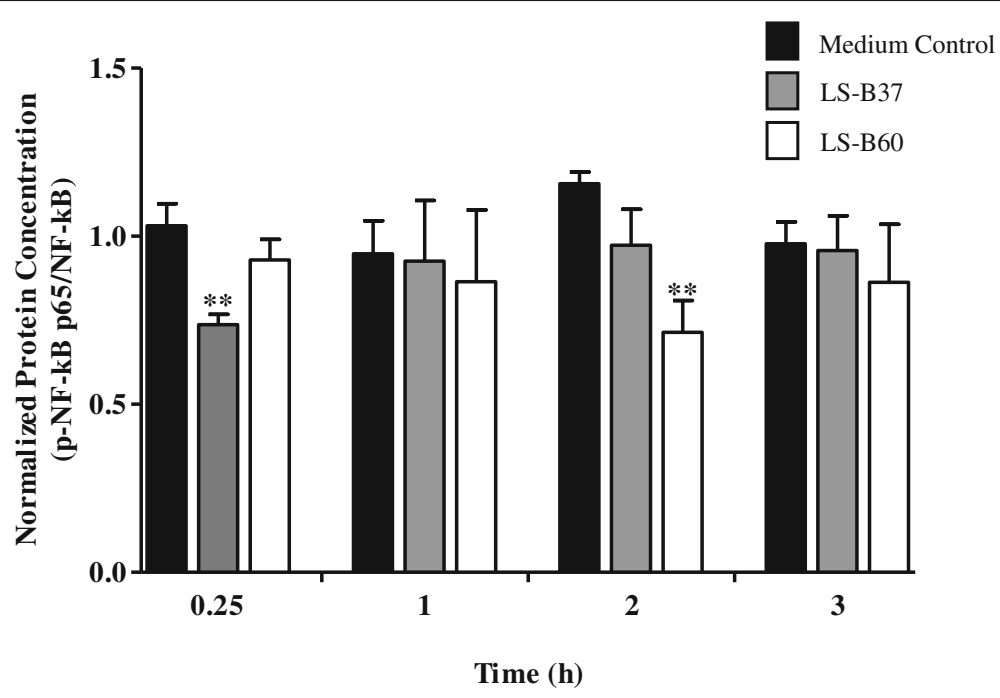

Fig. 3 L. salivarius strains suppress H. pylori-activated NF-KB in AGS gastric epithelial cells. H. pylori-stimulated AGS cells were incubated with medium control or LCM of LS-B37 and LS-B60 for $0.25,0.5,1$, 2, and $3 \mathrm{~h}$. Concentration of activated NF-KB were measured by Western blot analysis using antibodies to $\mathrm{p}-\mathrm{NF}-\mathrm{KB} \mathrm{p} 65$ and NF-KB p65. Relative protein concentration was quantified by densitometry and activated transcription factor ( $\mathrm{p}$ NF-KB p65 [Ser 536]) was normalized to non-activated counterpart (NF-KB p65). The results were from three independent experiments and expressed as the mean $\pm \mathrm{SEM},{ }^{* *} p<0.01$ as compared to medium control

affect IL-8 suppression (Fig. 5, Additional file 6). Treatment of LS-B60 LCM with either $\alpha$-amylase or proteinase $\mathrm{K}$ resulted in the loss of IL-8 inhibitory activity as compared to media control $(p>0.1003$ and $p>0.0972$, respectively) and non-treated LCM ( $>4$ fold change, $p<0.001$ and $p<0.001$, respectively). The treatment with lipase or trypsin affected IL-8 suppression of LS-B60 LCM by 4-fold as compared to non-treated LCM $(p<0.001$ and $p<0.001$, respectively) although LS-B60 LCM retained some suppression of IL-8 production that was statistically different from media control $(p<0.01$ and $p<0.05$, respectively). No effect on IL-8 suppression was detected when LS-B60 LCM was treated with lysozyme (Fig. 5, Additional file 6). These results suggest that the inhibitory substance of LS-B37 is polysaccharide, whereas the one of LS-B60 is complex consisting of components of polysaccharide, protein and lipid. On the other hand, LS-B60 may produce multiple immunomodulating substances like glycoproteins or lipoproteins. As lysozyme had no effect on IL-8 suppression by LCM from either strain, the peptidoglycan of these lactobacilli is most likely not involved.

\section{Discussion}

Persistent colonization of H. pylori results in chronic inflammation which predisposes infected people to severe peptic ulcer disease and gastric cancer [30]. Among several factors, pro-inflammatory cytokines and chemokines are the main mediators of mucosal inflammation and damage $[4,5]$. IL-8 is a key chemokine in neutrophil infiltration $[7,8]$ that is associated with disease severity $[14,16]$ and considered a potential prognostic and predictive cancer biomarker [31]. In fact, whole genome analysis of $H$. pylori-exposed AGS gastric epithelial cells revealed that after a $3 \mathrm{~h}$ exposure IL-8 is the single most up-regulated gene among $>38,000$ genes tested [32].

Specific strains of Lactobacillus have been shown to diminish $H$. pylori-induced IL-8 production in vitro and in vivo [23-25]. We have identified anti-inflammatory Lactobacillus spp. which suppress IL-8 secretion by $H$. pylori-induced AGS cells. Among these strains, it is interesting that $L$. salivarius strains B37 and B60 did not suppress IL-8 gene transcription at $4 \mathrm{~h}$ of co-culture [26]. It was previously reported that $L$. casei VSL\#3 suppressed TNF-induced secretion of the T-cell chemokine interferon-inducible protein (IP-10) secretion by Mode$\mathrm{K}$ intestinal epithelial cells without inhibiting IP-10 gene transcription. Study of the mechanism underlying this observation revealed that $L$. casei impairs vesicular pathways important for the secretion of IP-10 and the chemokine is subsequently degraded [33]. In an attempt to characterize the mechanism involved in the suppression of IL-8 secretion by LS-B37 and LS-B60, we first investigated the effect on IL- 8 gene expression by LCM of LS-B37 and LS-B60 at various time points. Our data demonstrated that both LCM reduced IL-8 gene expression as early as a $2 \mathrm{~h}$ co-culture and the reduction by LS-B37 LCM continued at $4 \mathrm{~h}$. Interference with IL-8 gene expression by probiotic microbes has been reported to occur at different time points of co-culture. L. gasseri 

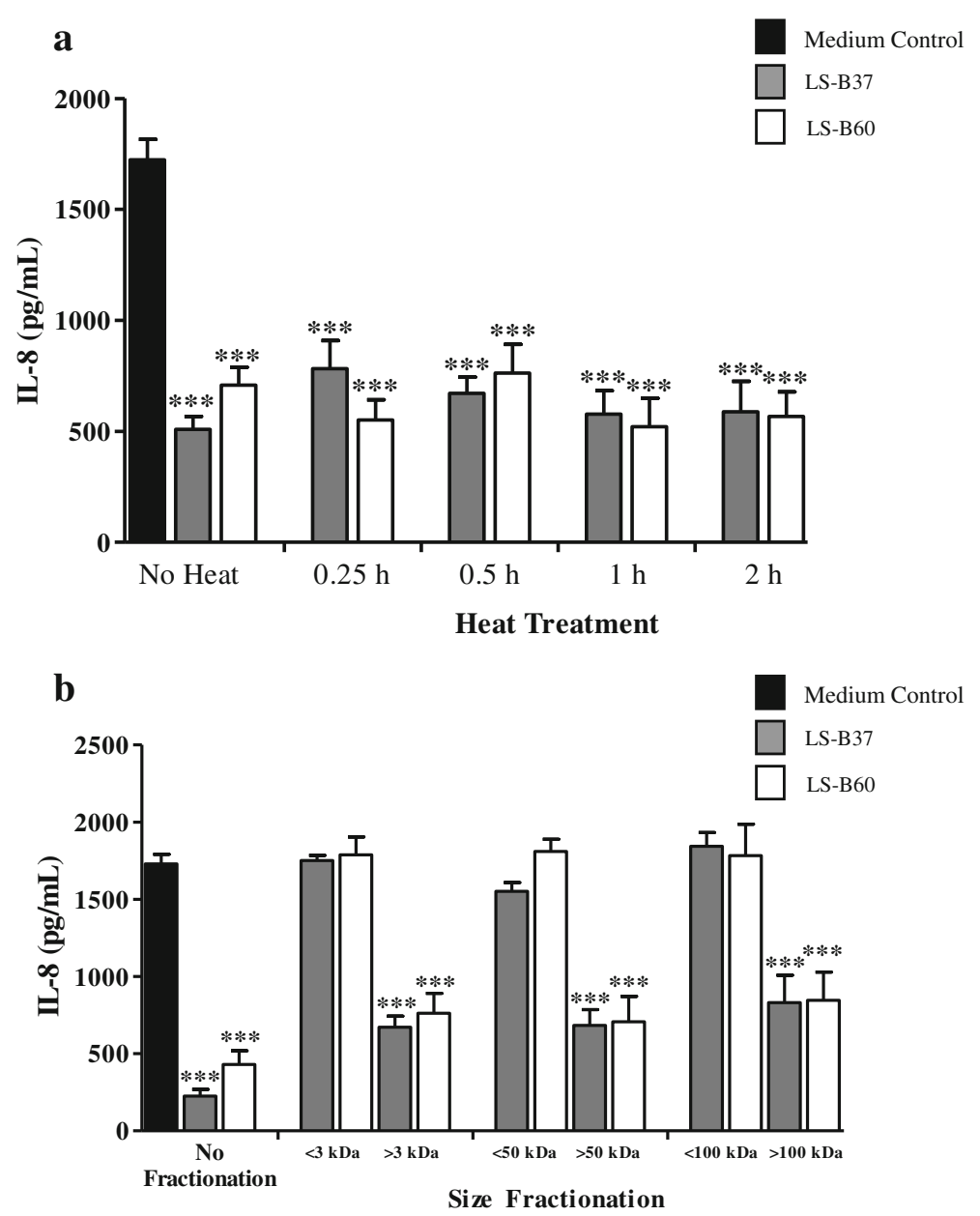

Fig. 4 IL-8 suppression by heat-treated and fractionated LCM of L. salivarius. LCM of LS-B37 and LS-B60 were either heat treated (a) or fractionated by using Amicon centrifugal filter (b) and tested for the suppression of IL-8 production using a Quantikine Human IL-8 Immunoassay. The results were from three independent experiments in triplicate and expressed as the mean \pm SEM, ${ }^{* * *} p<0.001$ as compared to medium control

OLL2716 (LG21) inhibited H. pylori-induced IL-8 gene expression by MKN45 gastric epithelial cells only at $6 \mathrm{~h}$ of co-culture [25]. On the contrary, Saccharomyces boulardii reduced IL-1 $\beta$-induced IL- 8 mRNA levels in HT29 colonic epithelial cells at all time points studied from 0.5 to $4 \mathrm{~h}$ [34]. This study also demonstrated that LCM from LS-B37 and LS-B60 suppressed the activation of $\mathrm{NF}-\mathrm{kB}$ at different time points $(15 \mathrm{~min}$ and $2 \mathrm{~h}$, respectively) but did not interfere with p-c-Jun activation. It has been demonstrated that IL-8 gene transcription in gastric epithelial cells requires the activation of both NF-kB and AP-1 [35], and a mutation in the IL- 8 gene at the NF- $\mathrm{kB}$ binding site alone results in the inhibition of IL-8 gene expression $[35,36]$. Therefore, suppression of only NF- $\mathrm{kB}$ activation by LCM of LS-B37 and LS-B60 should be sufficient for inhibiting IL- 8 production by these lactobacilli. Anti-inflammatory $L$. salivarius B101 and $L$. rhamnosus B103 were also shown to suppress only p-
NF-кB activated by $H$. pylori but the suppression occurred at various time points [26].

With an increase in the interest of anti-inflammatory Lactobacillus for $H$. pylori treatment, the molecular nature of immunomodulating substances has been investigated in Lactobacillus spp. Among several factors influencing host immune response, exopolysaccharides, which are extracellular polysaccharides attached to the bacterial cell surface or secreted into the extracellular environment, have been recognized to influence immune signaling [37]. In this study, the IL-8-suppressing substance in LCM of LS-B37 was a heat-stable, $\alpha$-amylase -sensitive factor with a molecular size $>100 \mathrm{kDa}$ suggesting the production of an immunomodulatory exopolysaccharide by LS-B37. Exopolysaccharides of beneficial bacteria have long been shown to act as immunomodulating agents and their contributions to immune stimulation and immune suppression have been investigated in 


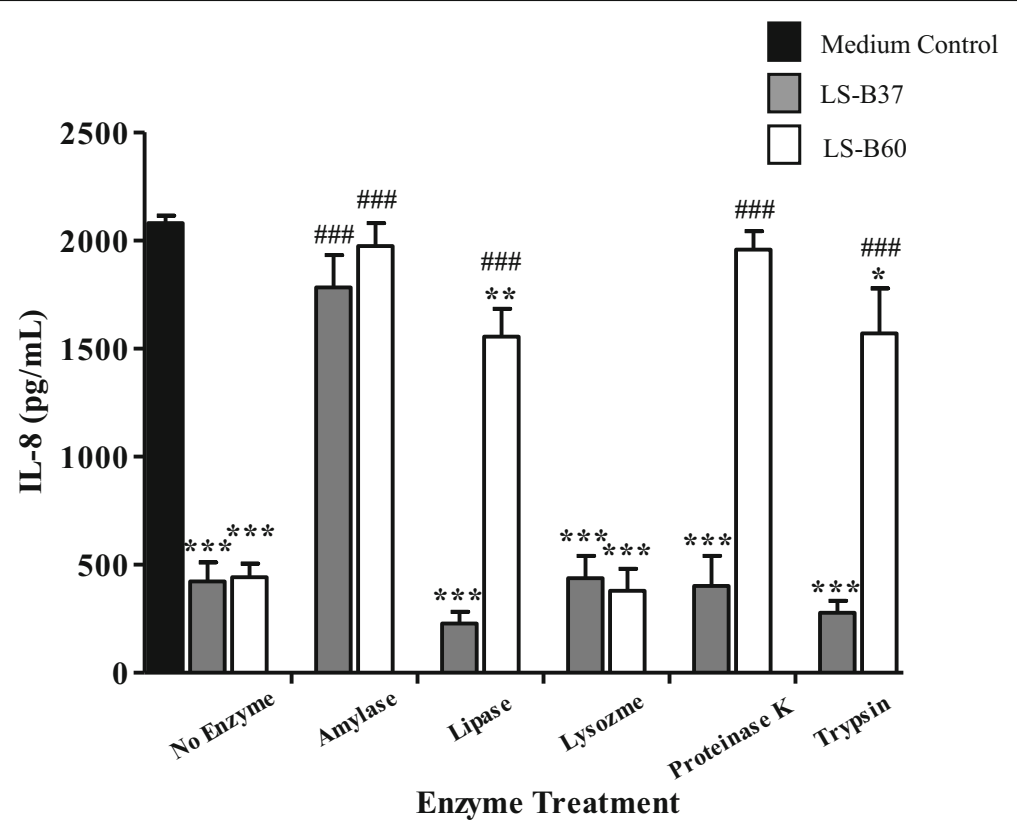

Fig. 5 Enzyme sensitivity of the immunomodulatory substances in LCM of L. salivarius. Substances in LCM of LS-B37 and LS-B60 were incubated with enzymes a-amylase, lipase, lysozyme, proteinase K and trypsin and the effect on IL-8 production was tested using a Quantikine Human IL-8 Immunoassay. The experiments were performed three times in triplicate and the results represented the mean $\pm \mathrm{SEM},{ }^{*} p<0.05,{ }^{* *} p<0.01,{ }^{* * *} p<0.001$ as compared to medium control, $\#$ \#\#\# 0.001 as compared to non-treated LCM

various aspects. Soluble polysaccharides with molecular weights between 60 and $2460 \mathrm{kDa}$ of Bifidobacterium adolescentis M101-4 were found to stimulate the proliferation of murine splenocytes, suggesting their immunomodulation activity [38]. Polysaccharide-peptidoglycan complex derived from Lactobacillus casei strain Shirota inhibited the release of IL-6 in LPS-stimulated large intestinal lamina propria mononuclear cells isolated from mice with chronic colitis and in RAW264.7 cells in vitro [39]. Pretreatment of exopolysaccharides obtained from Bifidobacterium longum BCRC 14634 suppressed LPSinduced cell growth inhibition and release of TNF- $\alpha$ from J774A.1 macrophages [40]. Exopolysaccharides with molecular weights $\leq 70 \mathrm{kDa}$ obtained from the culture medium of Lactobacillus confusus TISTR 1498 were observed to induce the production of nitric oxide and cytokines TNF- $\alpha$, IL-1 $\beta$, IL- 6 and IL-10 through the activation of NF- $\mathrm{KB}$ and JNK pathways [41]. In addition, an exopolysaccaride of Lactobacillus rhamnosus GG alleviated inflammatory cytokines IL-6, IL-12 and TNF- $\alpha$ in LPS-induced IPEC-J2 porcine intestinal epithelial cells at mRNA level by attenuation of MAPK and NF-kB signaling activations [42].

On the contrary to LS-B37, LS-B60 LCM is sensitive to $\alpha$-amylase, lipase, proteinase $\mathrm{K}$ and trypsin albeit with different magnitudes. It is probable that immunomodulatory substance(s) in LCM of LS-B60 is complex consisting of components of polysaccharide, protein and lipid. However, our result could not exclude the possibility that LS-B60 produces multiple immunomodulatory substances such as glycoproteins and lipoproteins. Bacterial glycoproteins have been identified [43] and secreted glycoproteins were reported in L. plantarum WCFS1 [44] and L. rhamnosus GG [45]. Glycoproteins of L. plantarum WCFS1 are thought to be recognized by the DC-specific ICAM-3-grabbing non-integrin (DCSIGN) receptor and thereby eliciting specific cytokine production and immune responses in immature human dendritic cells [44]. Anti-inflammatory activity of cellassociated glycoprotein was recently reported in $L$. plantarum L67 for the protection of inflammation caused by cadmium ion in RAW 264.7 cells by suppressing the expression of AP-1 (c-Jun and c-Fos), mitogen-activated protein kinases (ERK, JNK and $\mathrm{p} 38$ ), and inducible nitric oxide synthase [46]. The immunomodulatory effect of bacterial lipoprotein (BLP) was also demonstrated in $E$. coli Nissle 1917 in that BLP acts like the conditioned medium in the modulation of T-cell cycle progression by binding to toll-like receptor- 2 which may downregulate the expansion of newly recruited $\mathrm{T}$ cells into the mucosa and limit intestinal inflammation [47].

The structure and composition of polysaccharides and other biological substances are diverse among microbes and this variation may contribute to the different immunomodulation of host immune responses. Although we have not performed purification of bioactive substances, 
our initial characterization suggests the nature of different anti-inflammatory substances produced by LS-B37and LS-B60. Further studies are required to determine the exact molecular nature and function of these substances in the modulation of immune response to $H$. pylori infection.

\section{Conclusions}

In this study, we have provided evidence that human gastric-derived $L$. salivarius strains B37 and B60 produce anti-inflammatory substances that suppress IL- 8 production by $H$. pylori-induced AGS cells through the attenuation of NF- $\kappa B$ activation. Large, heat-stable bioactive substances produced by these two strains differ in enzymatic sensitivity. The immunomodulatory substance of $L$. salivarius B37 is similar to a polysaccharide, while that of LS-B60 is more structurally complex or includes multiple components such as glycoprotein and lipoprotein. These lactobacilli have potential as probiotics and their immunomodulatory substances may be pharmacologic agents for treatment of $H$. pylori-associated diseases.

\section{Methods}

Bacterial strains, cell line and culture conditions

Lactobacillus salivarius strains B37, B60, and B78 previously isolated from gastric biopsies of dyspeptic patients [48] were obtained from the stock culture maintained at the Department of Microbiology, Faculty of Medicine, Chulalongkorn University. Bacterial stock cultures were stored at $-80{ }^{\circ} \mathrm{C}$ in deMan Rogosa Sharpe (MRS) broth (Oxoid, Hampshire, UK) containing $10 \%$ (vol/vol) glycerol. All lactobacilli were cultured on MRS agar in an anaerobic chamber (Concept Plus, Ruskinn Technology, UK) $\left(10 \% \mathrm{CO}_{2}, 10 \% \mathrm{H}_{2}\right.$, and $\left.80 \% \mathrm{~N}_{2}\right)$ at $37{ }^{\circ} \mathrm{C}$ for $24 \mathrm{~h}$. Helicobacter pylori ATCC 43504 (ATCC, Manassas, VA, USA) was grown on Columbia agar (Oxoid, England) supplemented with $7 \%(\mathrm{v} / \mathrm{v})$ horse serum (Gibco New Zealand Ltd, Auckland, New Zealand) and $7 \%$ (v/v) sheep blood at $37{ }^{\circ} \mathrm{C}$ for $48 \mathrm{~h}$ under microaerophilic conditions ( $\left.6-12 \% \mathrm{O}_{2}, 5-8 \% \mathrm{CO}_{2}\right)$ using gas generation sachets (Anaero Pack-MicroAero, Mitsubishi Gas Chemical, Japan) AGS human gastric adenocarcinoma epithelial cells (ATCC CRL-1739) obtained from the American Type Culture Collection (Manassas, VA, USA) were cultured as a monolayer ( $>80 \%$ confluence) in RPMI 1640 medium supplemented with $10 \%(\mathrm{v} / \mathrm{v})$ heat-inactivated fetal bovine serum (Gibco-Invitrogen, USA) at $37{ }^{\circ} \mathrm{C}$ and $5 \% \mathrm{CO}_{2}$ atmosphere for $48 \mathrm{~h}$. AGS cells were passaged every 2-3 days. Adherent cells were detached from the flask with $0.25 \%(\mathrm{v} / \mathrm{v})$ trypsin in 1 mM EDTA (Gibco-Invitrogen, USA), resuspended in fresh medium and used in the co-culture assay.

\section{Preparation of Lactobacillus conditioned media}

Lactobacillus-conditioned media (LCM) were prepared as previously described [49]. L. salivarius strains were first cultured for $24 \mathrm{~h}$, then adjusted to an OD600 of 0.1 in MRS broth and incubated anaerobically for $48 \mathrm{~h}$. Cell free supernatants were collected by centrifugation at $4000 \times \mathrm{g}$ for $10 \mathrm{~min}$ at $4{ }^{\circ} \mathrm{C}$, filtered through a $0.22 \mu \mathrm{m}$ membrane filter (Minisart, Sartorius Stedim Biotech $\mathrm{GmbH}$, Goettingen, Germany) and concentrated by speed vacuum drying for $3 \mathrm{~h}$. (Savant instruments, Farmingdale, NY). Cell-free concentrated pellets were resuspended in an equal volume of RPMI 1640 medium (Gibco-Invitrogen, Carlsbad, CA, USA) and stored at $-20{ }^{\circ} \mathrm{C}$ until further use.

\section{Effect of LCM treatment on IL-8 production in the co- culture assay}

AGS gastric epithelial cells were treated with LCM and co-cultured with $H$. pylori to induce IL-8 production as previously described [50]. AGS cells $\left(2.0 \times 10^{4}\right.$ cells/well $)$ were pre-incubated as described above for $24 \mathrm{~h}$. The culture supernatant was replaced with fresh RPMI medium containing either $5 \%(\mathrm{v} / \mathrm{v})$ LCM alone or in combination with viable $H$. pylori ATCC $43504\left(6.0 \times 10^{6} \mathrm{CFU} /\right.$ well) and incubated under $5 \% \mathrm{CO}_{2}$ at $37{ }^{\circ} \mathrm{C}$ for $24 \mathrm{~h}$. Cell culture supernatants were collected by centrifugation at $125 \times \mathrm{g}$ for $7 \mathrm{~min}$ at $4{ }^{\circ} \mathrm{C}$. IL-8 concentrations in culture supernatants were determined using the Quantikine Human IL-8 Immunoassay Kit (R\&D Systems, Minneapolis, MN) according to the manufacturer's instructions. All experiments were tested at least three times in triplicate.

\section{Analysis of IL-8 gene expression by qRT-PCR}

The effects of LCM on the transcription of IL- 8 in $H$. pylori-treated AGS epithelial cells were determined by qRT- PCR as previously described $[26,51]$ with minor modifications. AGS cells $\left(5 \times 10^{5}\right.$ cells/well $)$ were cultured in a 24-well plate as described above and treated with viable $H$. pylori ATCC $43503\left(1.5 \times 10^{8} \mathrm{CFU} /\right.$ well $)$ with or without LCM (5\% v/v) for 2, 4, and $6 \mathrm{~h}$. Cell culture supernatants were removed by centrifugation and total RNA of treated AGS cells was extracted with TRIzol reagent (Invitrogen, USA) according to the manufacturer's instructions. Complementary DNA (cDNA) was reverse transcribed from $10 \mathrm{ng}$ total RNA using the SuperScript ${ }^{\circ}$ VILO $^{\mathrm{TM}}$ cDNA Synthesis kit (Invitrogen, USA), and qPCR was performed in a LightCycler ${ }^{\circ} 2.0$ (Roche, Germany) for 45 cycles of: $10 \mathrm{~s}$ at $95{ }^{\circ} \mathrm{C}, 10 \mathrm{~s}$ at $65{ }^{\circ} \mathrm{C}$, and $25 \mathrm{~s}$ at $72{ }^{\circ} \mathrm{C}$. The following primers were used to amplify cDNA fragments: IL-8 forward primer (5' -ACACTGCGCCAACACAGAAATTA-3'), and IL-8 reverse primer $\left(5^{\prime}\right.$-TTTGCTTGAAGTTTCACTGGCAT C-3'); Human glyceraldehyde-3-phosphate dehydrogenase 
(GAPDH) forward primer (5'-GCACCGTCAAGGCTG AGAAC-3'), and GAPDH reverse primer (5'-ATGG TGGTGAAGACGCCAGT-3'). IL-8 gene expression, relative to GAPDH, was calculated according to the $2^{-\Delta \Delta C p}$ method [52].

\section{Examination of cell signaling pathways by quantitative western blot}

The modulation of signaling pathways by LCM was examined by western blot as previously described with minor modifications [26, 28]. AGS cells $\left(2.0 \times 10^{6}\right.$ cells/ well) were cultured in a 6-well plate as described above. AGS cells were stimulated with $H$. pylori ATCC 43504 $\left(6.0 \times 10^{8} \mathrm{CFU} /\right.$ well $)$ in the presence or absence of LCM $(5 \% \mathrm{v} / \mathrm{v})$ for $0.25,0.5,1,2$, and $3 \mathrm{~h}$. Proteins were extracted from whole cell lysates of AGS-treated cells using Mammalian Protein Extraction Reagent (M-PER, Pierce Biotechnology, Illinois, USA) supplemented with Halt protease and phosphatase inhibitors (Pierce Biotechnology, Illinois, USA) according to the manufacturer's instructions. Protein concentrations from cell lysates were determined using the Pierce ${ }^{\circ}$ BCA protein assay kit (Pierce Biotechnology, Illinois, USA). Cell extracts were fractionated by $10 \%$ sodium dodecyl sulfate polyacrylamide gel electrophoresis (SDS-PAGE), transferred onto PVDF membranes (Bio-Rad, Philadelphia, USA) and blocked with $10 \%$ non-fat milk in TBST (50 mM Tris, $\mathrm{pH} 7.5,150 \mathrm{mM} \mathrm{NaCl}, 0.05 \%$ Tween 20). Blocked membranes were incubated with mouse antibodies against NF$\kappa B$ (p65), phospho-NF- $\mathrm{B}$ (p65), c-Jun, phospho-c-Jun (Santa Cruz Biotechnology, California, USA) and $\beta$-actin (Cell signaling Technology, Inc, MA, USA), washed with TBST and incubated with horseradish peroxidase-labeled goat anti-mouse secondary antibodies for $1 \mathrm{~h}$. Peroxidase signals were measured and imaged by $\mathrm{ChemiDoc}^{\mathrm{Tm}}$ XRS (Bio-Rad, Philadelphia, USA). Densitometric analyses for protein quantification were carried out using ImageJ $1.45 \mathrm{~s}$ software.

\section{Characterization of IL-8 suppressing substance(s) in LCM}

The properties of IL-8-suppressing substances produced by $L$. salivarius strains were tested for heat stability, size estimation, and enzyme sensitivity. Heat stability was assessed by heating LCM to $100{ }^{\circ} \mathrm{C}$ for $0.25,0.5,1$, and $2 \mathrm{~h}$. The sizes of active factors present in LCM were estimated by $3 \mathrm{kDa}, 50 \mathrm{kDa}$ and $100 \mathrm{kDa}$ Amicon Ultra-4 Centrifugal Filters (Millipore Ireland B.V.,Tullagreen, Carrigtwohill, County Cork, Ireland) according to the manufacturer's instruction. Enzyme sensitivity of LCM was tested by incubation with various enzymes: $\alpha$ amylase in $20 \mathrm{mM}$ sodium acetate, $7 \mathrm{mM}$ sodium chloride ( $\mathrm{pH}$ 6.9); lipase and lysozyme each in $50 \mathrm{mM}$ Tris- $\mathrm{HCl}(\mathrm{pH}$ 7.2); proteinase $\mathrm{K}$ and trypsin each in $50 \mathrm{mM}$ Tris- $\mathrm{HCl}$ (pH 7.5-7.6). Each enzyme (Sigma,
USA) was used at a final concentration of $1 \mathrm{mg} / \mathrm{mL}$ and incubated at $37^{\circ} \mathrm{C}$ for $6 \mathrm{~h}$, except for amylase and lysozyme which were incubated at $25^{\circ} \mathrm{C}$. Enzymes were inactivated by heating each enzyme-treated $\mathrm{LCM}$ at $100{ }^{\circ} \mathrm{C}$ for 10 min. All treated samples were tested for IL-8 suppressive activity in the co-culture assay described above.

\section{Statistical analysis}

All experiments were performed three times each in triplicate and the results were reported as mean \pm standard deviation (SD) or standard error of mean (SEM). The data were analyzed in GraphPad Prism 5 using the unpaired $t$ test with one-tailed distribution and considered statistically significant at a $p$-value $\leq 0.05$, unless otherwise stated.

\section{Additional files}

Additional file 1: Raw data used to generate Fig. 1. (DOCX 16 kb) Additional file 2: Raw data used to generate Fig. 2. (DOCX 14 kb) Additional file 3: Figure S1. Representative result of Western blot analysis on suppressive effects of LCM of LS-B37 and LS-B60 on H. pyloriactivated NF-KB in AGS cells; Table S1 Relative levels of $\mathrm{p}-\mathrm{NF-KB}$ and NF$\mathrm{KB}$ at various time points. (DOCX $241 \mathrm{~kb}$ )

Additional file 4: Table S2A. Raw data used to generate Fig. 4a showing the effect of heat treatment on LCM of LS-B37; Table S2B Raw data used to generate Fig. 4a showing the effect of heat treatment on LCM of LS-B60. (DOCX 20 kb)

Additional file 5: Table S3A. Raw data used to generate Fig. 4b showing the effect of size fractionation on LCM of LS-B37; Table S3B Raw data used to generate Fig. $4 \mathrm{~b}$ showing the effect of size fractionation on LCM of LS-B60. (DOCX $21 \mathrm{~kb})$

Additional file 6: Table S4A. Raw data used to generate Fig. 5 showing the effect of enzyme treatment on LCM of LS-B37; Table S4B Raw data used to generate Fig. 5 showing the effect of enzyme treatment on LCM of LS-B60. (DOCX $21 \mathrm{~kb})$

\section{Abbreviations}

ELISA: Enzyme-linked immunosorbent assay; IL-8: Interleukin-8; LCM: Lactobacillus conditioned medium; LS: Lactobacillus salivarius; MRS: deMan Rogosa Sharpe; NF-kB: Nuclear factor-kappa B; qRTPCR: Quantitative reverse transcription polymerase chain reaction; SDSPAGE: Sodium dodecyl sulfate polyacrylamide gel electrophoresis

\section{Acknowledgements \\ The authors would like to thank Chulalongkorn University, the Thailand Research Fund and the National Research Council of Thailand for financial support. \\ Funding \\ This study was supported by the Ratchadapiseksompotch Fund from Faculty of Medicine, Chulalongkorn University (Grant No. RA55/83), the $90^{\text {th }}$ Anniversary of Chulalongkorn University Fund (Grant No. 23, 2/2557) from Chulalongkorn University Graduate School and the Research Grant for Graduate Studies from the National Research Council of Thailand (Fiscal year 2014 No. 57/045). WP was sponsored by a Ph.D. Royal Golden Jubilee Scholarship from the Thailand Research Fund Grant No. PHD/0316/2552.}




\section{Authors' contributions}

JKS, JV and ST conceived and designed the study. WP designed and performed the experiments. WP, ST, JKS and JV wrote the manuscript. All authors read and approved the final manuscript.

\section{Competing interests}

The authors declare that they have no competing interests.

\section{Consent for publication}

Not applicable.

\section{Ethics approval and consent to participate}

Not applicable.

\section{Author details}

${ }^{1}$ Interdisciplinary Program of Medical Microbiology, Graduate School, Chulalongkorn University, Bangkok, Thailand. ${ }^{2}$ Texas Children's Microbiome Center, Department of Pathology, Texas Children's Hospital, Houston, TX, USA. ${ }^{3}$ Department of Pathology \& Immunology, Baylor College of Medicine Houston, TX, USA. ${ }^{4}$ Department of Microbiology, Faculty of Medicine, Chulalongkorn University, Bangkok 10330, Thailand.

Received: 26 May 2016 Accepted: 11 October 2016

\section{Published online: 18 October 2016}

\section{References}

1. Blaser MJ, Atherton JC. Helicobacter pylori persistence: biology and disease J Clin Invest. 2004;113:321-33.

2. World Health Organisation. Schistosomes, liver flukes and Helicobacter pylori. IARC Working Group on the Evaluation of Carcinogenic Risks to Humans. Lyon, 7-14 June 1994. IARC Monogr Eval Carcinog Risks Hum. 1994;61:1-241.

3. Crabtree JE. Gastric mucosal inflammatory responses to Helicobacter pylori. Aliment Pharmacol Ther. 1996;10 Suppl 1:29-37.

4. Chiba T, Marusawa H, Seno H, Watanabe N. Mechanism for gastric cancer development by Helicobacter pylori infection. J Gastroenterol Hepatol. 2008; 23:1175-81.

5. Muller A, Solnick JV. Inflammation, immunity, and vaccine development for Helicobacter pylori. Helicobacter. 2011;16 Suppl 1:26-32.

6. Crabtree JE. Immune and inflammatory responses to Helicobacter pylori infection. Scand J Gastroenterol Suppl. 1996;215:3-10.

7. Baggiolini M, Walz A, Kunkel SL. Neutrophil-activating peptide-1/interleukin 8, a novel cytokine that activates neutrophils. J Clin Invest. 1989:84:1045-9.

8. Hammond ME, Lapointe GR, Feucht PH, Hilt S, Gallegos CA, Gordon CA, Giedlin MA, Mullenbach G, Tekamp-Olson P. IL-8 induces neutrophil chemotaxis predominantly via type I IL-8 receptors. J Immunol. 1995;155:1428-33.

9. Crabtree JE, Lindley IJ. Mucosal interleukin-8 and Helicobacter pyloriassociated gastroduodenal disease. Eur J Gastroenterol Hepatol. 1994;6 Suppl 1:S33-8.

10. Crabtree JE, Wyatt Jl, Trejdosiewicz LK, Peichl P, Nichols PH, Ramsay N, Primrose JN, Lindley IJ. Interleukin-8 expression in Helicobacter pylori infected, normal, and neoplastic gastroduodenal mucosa. J Clin Pathol. 1994:47:61-6.

11. Fan XG, Chua A, Fan XJ, Keeling PW. Increased gastric production of interleukin-8 and tumour necrosis factor in patients with Helicobacter pylori infection. J Clin Pathol. 1995:48:133-6.

12. Suzuki M, Mori M, Miyayama A, Iwai N, Tsunematsu N, Oonuki M, Suzuki H, Hibi T, Ishii H. Enhancement of neutrophil infiltration in the corpus after failure of Helicobacter pylori eradication. J Clin Gastroenterol. 1997;25 Suppl 1:S222-8.

13. Suzuki H, Mori M, Sakaguchi AA, Suzuki M, Miura S, Ishii $H$. Enhanced levels of C-X-C chemokine, human GROalpha, in Helicobacter pylori-associated gastric disease. J Gastroenterol Hepatol. 1998;13:516-20.

14. Yamaoka Y, Kita M, Kodama T, Sawai N, Kashima K, Imanishi J. Expression of cytokine mRNA in gastric mucosa with Helicobacter pylori infection. Scand J Gastroenterol. 1995;30:1153-9.

15. Xuan J, Deguchi R, Yanagi H, Ozawa H, Urano T, Ogawa Y, Fukuda R, Kojima S, Nishina M, Sudo H, et al. Relationship between gastric mucosal IL-8 levels and histological gastritis in patients with Helicobacter pylori infection. Tokai J Exp Clin Med. 2005;30:83-8.

16. Yamada S, Kato S, Matsuhisa T, Makonkawkeyoon L, Yoshida M, Chakrabandhu T, Lertprasertsuk N, Suttharat P, Chakrabandhu B, Nishiumi S, et al. Predominant mucosal IL-8 mRNA expression in non-cagA Thais is risk for gastric cancer. World J Gastroenterol. 2013;19:2941-9.

17. Malfertheiner P, Peitz U, Treiber G. What constitutes failure for Helicobacter pylori eradication therapy? Can J Gastroenterol. 2003;17(Suppl B):53B-7.

18. O'Connor A, Gisbert JP, O'Morain C, Ladas S. Treatment of Helicobacter pylori infection. Helicobacter. 2015:20 Suppl 1:54-61.

19. Malfertheiner P, Megraud F, O'Morain CA, Atherton J, Axon AT, Bazzoli F, Gensini GF, Gisbert JP, Graham DY, Rokkas T, et al. Management of Helicobacter pylori infection-the Maastricht IV/ Florence Consensus Report. Gut. 2012;61:646-64.

20. Ruggiero P. Use of probiotics in the fight against Helicobacter pylori. World J Gastrointest Pathophysiol. 2014;5:384-91.

21. Homan M, Orel R. Are probiotics useful in Helicobacter pylori eradication? World J Gastroenterol. 2015;21:10644-53.

22. Lee JS, Paek NS, Kwon OS, Hahm KB. Anti-inflammatory actions of probiotics through activating suppressor of cytokine signaling (SOCS) expression and signaling in Helicobacter pylori infection: a novel mechanism. J Gastroenterol Hepatol. 2010;25:194-202.

23. Ryan KA, O'Hara AM, van Pijkeren JP, Douillard FP, O'Toole PW. Lactobacillus salivarius modulates cytokine induction and virulence factor gene expression in Helicobacter pylori. J Med Microbiol. 2009;58:996-1005.

24. Yang YJ, Chuang CC, Yang HB, Lu CC, Sheu BS. Lactobacillus acidophilus ameliorates $\mathrm{H}$. pylori-induced gastric inflammation by inactivating the Smad7 and NFkappaB pathways. BMC Microbiol. 2012;12:38.

25. Tamura A, Kumai $H$, Nakamichi N, Sugiyama T, Deguchi $R$, Takagi A, Koga $Y$. Suppression of Helicobacter pylori-induced interleukin-8 production in vitro and within the gastric mucosa by a live Lactobacillus strain. J Gastroenterol Hepatol. 2006;21:1399-406.

26. Thiraworawong T, Spinler JK, Werawatganon D, Klaikeaw N, Venable SF, Versalovic J, Tumwasorn S. Anti-inflammatory properties of gastric-derived Lactobacillus plantarum XB7 in the context of Helicobacter pylori infection. Helicobacter. 2014;19:144-55.

27. Chu SH, Kim H, Seo JY, Lim JW, Mukaida N, Kim KH. Role of NF-kappaB and AP-1 on Helicobater pylori-induced IL-8 expression in AGS cells. Dig Dis Sci. 2003;48:257-65

28. Seo JH, Lim JW, Kim H, Kim KH. Helicobacter pylori in a Korean isolate activates mitogen-activated protein kinases, AP-1, and NF-kappaB and induces chemokine expression in gastric epithelial AGS cells. Lab Invest. 2004:84:49-62.

29. Naumann M. Pathogenicity island-dependent effects of Helicobacter pylor on intracellular signal transduction in epithelial cells. Int J Med Microbiol. 2005;295:335-41.

30. Naumann M, Crabtree JE. Helicobacter pylori-induced epithelial cell signalling in gastric carcinogenesis. Trends Microbiol. 2004;12:29-36.

31. Lee KE, Khoi PN, Xia Y, Park JS, Joo YE, Kim KK, Choi SY, Jung YD. Helicobacter pylori and interleukin-8 in gastric cancer. World J Gastroenterol. 2013:19:8192-202.

32. Eftang LL, Esbensen $Y$, Tannaes TM, Bukholm IR, Bukholm G. Interleukin-8 is the single most up-regulated gene in whole genome profiling of $\mathrm{H}$. pylori exposed gastric epithelial cells. BMC Microbiol. 2012;12:9.

33. Hoermannsperger G, Clavel T, Hoffmann M, Reiff C, Kelly D, Loh G, Blaut M, Holzlwimmer G, Laschinger M, Haller D. Post-translational inhibition of IP-10 secretion in IEC by probiotic bacteria: impact on chronic inflammation. PLOS One. 2009:4:e4365

34. Sougioultzis S, Simeonidis S, Bhaskar KR, Chen X, Anton PM, Keates S, Pothoulakis C, Kelly CP. Saccharomyces boulardii produces a soluble antiinflammatory factor that inhibits NF-kappaB-mediated IL-8 gene expression. Biochem Biophys Res Commun. 2006;343:69-76.

35. Mukaida N, Okamoto S, Ishikawa Y, Matsushima K. Molecular mechanism of interleukin-8 gene expression. J Leukoc Biol. 1994;56:554-8.

36. Sharma SA, Tummuru MK, Blaser MJ, Kerr LD. Activation of IL-8 gene expression by Helicobacter pylori is regulated by transcription factor nuclear factor-kappa B in gastric epithelial cells. J Immunol. 1998;160:2401-7.

37. Wells JM. Immunomodulatory mechanisms of lactobacilli. Microb Cell Factories. 2011;10 Suppl 1:S17.

38. Hosono A, Lee J, Ametani A, Natsume M, Hirayama M, Adachi T, Kaminogawa S. Characterization of a water-soluble polysaccharide fraction with immunopotentiating activity from Bifidobacterium adolescentis M101-4. Biosci Biotechnol Biochem. 1997;61:312-6.

39. Matsumoto S, Hara T, Hori T, Mitsuyama K, Nagaoka M, Tomiyasu N, Suzuk A, Sata M. Probiotic Lactobacillus-induced improvement in murine chronic 
inflammatory bowel disease is associated with the down-regulation of proinflammatory cytokines in lamina propria mononuclear cells. Clin Exp Immunol. 2005;140:417-26.

40. Wu MH, Pan TM, Wu YJ, Chang SJ, Chang MS, Hu CY. Exopolysaccharide activities from probiotic bifidobacterium: immunomodulatory effects (on J774A.1 macrophages) and antimicrobial properties. Int J Food Microbiol. 2010;144:104-10

41. Surayot U, Wang J, Seesuriyachan P, Kuntiya A, Tabarsa M, Lee Y, Kim JK Park W, You S. Exopolysaccharides from lactic acid bacteria: structural analysis, molecular weight effect on immunomodulation. Int J Biol Macromol. 2014:68:233-40.

42. Gao K, Wang C, Liu L, Dou X, Liu J, Yuan L, Zhang W, Wang H. Immunomodulation and signaling mechanism of Lactobacillus rhamnosus GG and its components on porcine intestinal epithelial cells stimulated by lipopolysaccharide. J Microbiol Immunol Infect. 2015. doi:10.1016/j.jmii.2015. 05.002 .

43. Abu-Qarn M, Eichler J, Sharon N. Not just for Eukarya anymore: protein glycosylation in Bacteria and Archaea. Curr Opin Struct Biol. 2008;18:544-50.

44. Remus DM, Kleerebezem M, Bron PA. An intimate tete-a-tete - how probiotic lactobacilli communicate with the host. Eur J Pharmacol. 2011;668 Suppl 1:S33-42.

45. Lebeer S, Claes IJ, Balog Cl, Schoofs G, Verhoeven TL, Nys K, von Ossowski I, de Vos WM, Tytgat HL, Agostinis P, et al. The major secreted protein Msp1/p75 is O-glycosylated in Lactobacillus rhamnosus GG. Microb Cell Fact. 2012;1 1:15.

46. Song S, Oh S, Lim KT. Lactobacillus plantarum L67 glycoprotein protects against cadmium chloride toxicity in RAW 264.7 cells. J Dairy Sci. 2016;99: 1812-21.

47. Sturm A, Rilling K, Baumgart DC, Gargas K, Abou-Ghazale T, Raupach B, Eckert J, Schumann RR, Enders C, Sonnenborn U, et al. Escherichia coli Nissle 1917 distinctively modulates T-cell cycling and expansion via toll-like receptor 2 signaling. Infect Immun. 2005;73:1452-65.

48. Panpetch W. Detection of Lactobacillus in the stomach of dyspeptic patients and its role in the suppression of TNF production in vitro. Graduate School (M.Sc. Thesis). Thailand: Chulalongkorn University; 2008

49. Taweechotipatr M, Iyer C, Spinler JK, Versalovic J, Tumwasorn S. Lactobacillus saerimneri and Lactobacillus ruminis: novel human-derived probiotic strains with immunomodulatory activities. FEMS Microbiol Lett. 2009;293:65-72.

50. Panpetch $W$, Thiraworawong T, Tumwasorn S. Human gastric biopsyderived lactobacilli suppress Helicobacter pylori-induced interleukin-8 production from gastric epithelial cells in vitro. Int J Interferon Cytokine Mediat Res. 2011;3:43-9.

51. Imaoka A, Shima T, Kato K, Mizuno S, Uehara T, Matsumoto S, Setoyama H, Hara T, Umesaki Y. Anti-inflammatory activity of probiotic Bifidobacterium: enhancement of IL-10 production in peripheral blood mononuclear cells from ulcerative colitis patients and inhibition of IL-8 secretion in HT-29 cells. World I Gastroenterol. 2008;14:2511-6.

52. Pfaffl MW. A new mathematical model for relative quantification in real-time RT-PCR. Nucleic Acids Res. 2001;29:e45.

\section{Submit your next manuscript to BioMed Central and we will help you at every step:}

- We accept pre-submission inquiries

- Our selector tool helps you to find the most relevant journal

- We provide round the clock customer support

- Convenient online submission

- Thorough peer review

- Inclusion in PubMed and all major indexing services

- Maximum visibility for your research

Submit your manuscript at www.biomedcentral.com/submit
Biomed Central 